\title{
BIOMETRIA DE FRUTOS E SEMENTES E TRATAMENTOS PRÉ-GERMINATIVOS EM SEMENTES DE Hymenaea courbaril
}

\author{
Jania Claudia Camilo dos Santos* \\ Dayane Mércia Ribeiro Silva* \\ Renato Nunes Costa* \\ Saymon Acchile Santos* \\ Lennon Kledson dos Santos Silva* \\ José Vieira Silva**
}

RESUMO: A caracterização de frutos e sementes de espécies florestais é fundamental para o conhecimento das condições ideais de germinação e seu uso na revegetação de ambientes degradados. Este trabalho teve por objetivo caracterizar biometricamente frutos e sementes e definir o método adequado para superação de dormência das sementes de Hymenaea courbaril. Foram mensurados comprimento, largura, espessura e massa de frutos e sementes, sendo posteriormente, as sementes submetidas aos seguintes tratamentos pré-germinativos: sementes sem tratamento (controle); ácido sulfúrico por 10; 20 e 30 minutos; escarificação mecânica; e imersão em água quente a $100{ }^{\circ} \mathrm{C}$ até resfriamento. Os dados biométricos foram submetidos à análise estatística descritiva e distribuição de frequência. Ao longo da germinação foram avaliadas a percentagem, índice de velocidade e tempo médio de germinação. Constatou-se que $15 \%$ da biomassa dos frutos foram alocadas para as sementes, $72 \%$ na casca e $13 \%$ na polpa farinácea. Os métodos pré-germinativos da escarificação química durante 30 minutos e mecânica apresentaram 80\% e 93\% da germinação, respectivamente. Os frutos e sementes de $H$. courbaril apresentaram ampla variação biométrica e de biomassa, o que constitui características importantes na germinação das sementes. Entre as classes, a biomassa variou entre 2,90 a 4,34 g. Os tratamentos que apresentaram germinação satisfatória foram ácido sulfúrico e lixa.

PALAVRAS- CHAVE: Alocação de biomassa; Dormência; Sementes florestais.

\footnotetext{
* Eng. Agrônomos e mestres pela Universidade Federal de Alagoas (UFAL), Brasil. E-mail: janya_claudia@yahoo.com

* Doutor em Agronomia. Docente do Programa de Pós-graduação em Agricultura e Ambiente, Universidade Federal de Alagoas (UFAL), Brasil.
} 


\section{BIOMETRY OF FRUITS AND SEEDS AND PRE-GERMINATION TREATMENTS OF Hymenaea courbaril SEEDS}

ABSTRACT: Fruit and seed characterization of forest species is crucial for ideal germination conditions and its use in the re-vegetation of degraded environments. Current research characterizes biometrically fruits and seeds and defines the method to overcome dormancy of Hymenaea courbaril seed. Length, width, thickness, mass of fruit and seeds were measured. Seeds underwent the following pre-germination treatments: seeds without any treatment (control); sulfuric acid for 10, 20 and 30 minutes; mechanical scarification; immersion in hot water at $100{ }^{\circ} \mathrm{C}$ until cooling. Biometric data underwent descriptive statistical analysis and frequency distribution. Percentage, speed index and mean germination period were assessed throughout germination. Results show that $15 \%$ of fruit biomass were allocated to seeds, namely, $72 \%$ in the rind and $13 \%$ in the pulp. Pre-germination method of chemical and mechanical scarification during 30 minutes provided 80 and $93 \%$ of germination, respectively. Fruits and seeds of $\mathrm{H}$. courbaril provided a wide biometric and biomass variation, forming important characteristics in seed germination. Biomass varied between 2.90 and $4.34 \mathrm{~g}$. Treatment with satisfactory germination were sulfuric acid and sandpaper.

KEY WORDS: Allocation of biomass; Dormancy; Forest seeds.

\section{INTRODUÇÃO}

A espécie arbórea Hymenaea courbaril Linnaeus, conhecida como jatobá, jutaí ou jataí, pertencente à família Fabaceae e ultimamente tem despertado o interesse de estudiosos e pesquisadores por possuir características de interesse econômico para medicina popular, alimentação, construção civil, entre outras. A espécie ainda apresenta ampla adaptabilidade em várias regiões e biomas do Brasil, e destaca-se entre as espécies vegetais de interesse para os programas de recuperação de áreas degradadas (CARVALHO, 1994; TAMAYO et al., 2008; MATHEUS et al., 2011).

Estudos voltados à produção de mudas florestais que apresentem boa qualidade fisiológica têm sido apontados para os programas de reflorestamentos, assim como a caracterização biométrica de frutos e sementes de espécies nativas, que assume papel relevante na identificação taxonômica, e permite obter informações 
necessárias sobre a variação fenológica entre espécies de um mesmo gênero ou que se desenvolveram em condições ambientais diferenciadas (CRUZ et al., 2001; GUSMÃO et al., 2006; ALVES et al., 2007; SILVA; CARVALHO, 2008; SANTOS et al., 2012; GONÇALVES et al., 2013; SILVA et al., 2014; DUARTE et al., 2015; MATOS et al., 2015; GOMES et al., 2016; PIRES NETO et al., 2016; SILVA et al., 2017; Santos et al., 2018; Santos et al., 2019), além de possibilitar maior aprimoramento na germinação e vigor das sementes (CARVALHO; NAKAGAWA, 2012; DUARTE et al., 2016).

Algumas espécies florestais não são capazes de germinar e/ou produzir plântulas normais, mesmo em condições ambientais favoráveis, o que desencadeia um mecanismo natural que retarda a germinação das sementes por consequência da restrição à entrada de água através do tegumento, processo este conhecido por dormência, dificultando o planejamento na produção de mudas para os programas de reflorestamento (BEWLEY; BLACK, 1994; CARVALHO; NAKAGAWA, 2012; MATOS et al., 2015; ABREU et al., 2017). De maneira prática, existem diferentes métodos para superar a dormência tegumentar das sementes, entre os quais se podem destacar: a escarificação química, escarificação mecânica e a exposição a altas temperaturas (COSTA et al., 2013; MONTANHA et al., 2018; SANTOS et al., 2019).

A escarificação química permite maior rapidez, praticidade e eficiência no processo germinativo, que varia em relação ao tempo de exposição da semente ao ácido e atua de acordo com a espessura tegumentar da semente; já a escarificação mecânica constitui uma opção mais prática e de baixo custo, eficaz para promover rapidez e uniformidade na germinação das sementes; a escarificação através do aumento da temperatura permite a penetração da água através do amolecimento do tegumento, uma vez que atua na degradação dos inibidores químicos (GUEDES et al., 2009; BRANCALION et al., 2011; SILVA et al., 2011; ATAÍDE et al., 2013).

Diante da necessidade e importância de estudos relacionados à propagação de espécies florestais nativas, este trabalho visa contribuir para eficiência destes processos de revegetação. Desta forma, este trabalho teve por objetivo caracterizar biometricamente frutos e sementes, e avaliar a eficiência de tratamentos prégerminativos na superação de dormência das sementes de $H$. courbaril L. 


\section{MATERIAL E MÉTODOS}

\subsection{LOCAL DO EXPERIMENTO E ORIGEM DO MATERIAL VEGETAL}

O trabalho foi realizado no Laboratório de Fisiologia Vegetal da Universidade Federal de Alagoas, Campus Arapiraca (AL) (0945’09” S; longitude: 36³9’40” W e $324 \mathrm{~m}$ de altitude). Os frutos de jatobá (Hymenaea courbaril L.) foram coletados na região de São Sebastião (AL) (0952'52,7' S; 036³2'28,1" W), completamente secos e quando apresentavam coloração amarronzada e/ou deiscência natural. Esta região é caracterizada pela transição entre a Zona da Mata e o Sertão Alagoano, e o clima classificado como tipo 'As' tropical com estação seca de verão, pela classificação de Köppen.

\subsection{AVALIAÇÕES BIOMÉTRICAS}

Após a coleta, os frutos foram acondicionados em sacos de nylon e conduzidos ao laboratório, onde foram realizados o beneficiamento, a extração e limpeza das sementes, as quais consistiram na quebra dos frutos e posterior extração da polpa farinácea das sementes, retirando-se as sementes danificadas. Os dados de biometria foram obtidos a partir de 50 frutos, distribuídos ao acaso em cinco lotes de 10 frutos, que após analisados e beneficiados, resultaram em um total de 150 sementes selecionadas. Os frutos e sementes foram mensurados quanto ao comprimento (C) aferido da base até o ápice; largura (L), aferido da maior extremidade horizontal; e espessura (E) medidas na linha mediana central, com auxílio de um paquímetro digital com precisão de $0,01 \mathrm{~mm}$, sendo posteriormente pesados em balança analítica com precisão de $0,001 \mathrm{~g}$.

\subsection{TESTE DE GERMINAÇÃO}

Após análise biométrica e beneficiamento das sementes, foi realizado um préteste de germinação das sementes de $H$. courbaril, utilizando as mesmas condições dos estudos pré-germinativos em câmara de germinação tipo Biochemical Oxigen 
Demand (BOD), regulada a temperatura de $27^{\circ} \mathrm{C}$ sob luz constante, semelhante ao tratamento controle. Posteriormente, sendo evidenciado que a espécie apresenta dormência tegumentar e que havia necessidade de efetuar diferentes métodos para a superação da dormência. Para o teste de superação de dormência, as sementes foram submetidas a seis tratamentos pré-germinativos, com cinco repetições de 20 sementes, cuja massa média adotada foi igual ou superior a 2,90 g baseado nas classes de distribuição de frequência da biometria.

Para os estudos dos tratamentos pré-germinativos, as sementes foram submetidas ao tratamento controle, ou seja, sementes sem nenhum tipo de método de superação de dormência; para escarificação química, sendo que para as sementes foram submersas em ácido sulfúrico $\left(\mathrm{H}_{2} \mathrm{SO}_{4}\right)$ concentrado $(96 \%$ p.a) durante os períodos de 10, 20 e 30 minutos; para escarificação mecânica, foi utilizada lixa $n^{\circ}$ 80 , sendo as sementes friccionadas manualmente até a ruptura do tegumento e aparecimento dos tecidos cotiledonares do lado oposto ao hilo/eixo embrionário e nas duas laterais; a imersão em água quente consistiu na utilização de $400 \mathrm{~mL}$ de água aquecida até atingir a temperatura de $100{ }^{\circ} \mathrm{C}$, controlada por termômetro.

Após a realização dos testes para a superação de dormência, as sementes foram submetidas à assepsia em hipoclorito de sódio a 2,5\%, durante três minutos para desinfestação e, posteriormente, lavados em água corrente. Em seguida, as sementes desinfestadas foram semeadas em caixas plásticas tipo "gerbox", sendo duas caixas por repetição, devido ao tamanho da semente, utilizando como substrato o papel "mata borrão", umedecido com quantidade de água equivalente a 2,5 vezes a massa do substrato não hidratado (BRASIL, 2009).

$\mathrm{O}$ experimento foi realizado em germinador tipo BOD, regulada a temperatura constante de $27{ }^{\circ} \mathrm{C}$ na presença de luz contínua. A contagem das sementes germinadas iniciou $192 \mathrm{~h}$ após a semeadura, sendo este o período da protrusão radicular e estendeu-se durante o período de 31 dias, quando ocorreu a estabilização da germinação. Os resultados foram expressos em percentagem de plântulas normais, considerando germinadas as sementes cuja radícula apresentou tamanho igual ou superior a 2,5 mm (BRASIL, 2009).

Foram avaliados os seguintes parâmetros: percentagem de germinação (GER) representada pela percentagem de sementes germinadas de cada tratamento; 
Índice de velocidade de germinação (IVG), representadas pelas contagens diárias; e tempo médio de germinação (TMG) com base no número de sementes germinadas diariamente.

\subsection{ANÁLISE ESTATÍSTICA}

Para análise dos dados biométricos foi realizada a distribuição de frequência e as características quantitativas foram submetidas à análise descritiva para determinação do valor mínimo, máximo, média, desvio padrão, assimetria, curtose e alocação de biomassa dos frutos e sementes. Para o teste de germinação foi utilizado o delineamento inteiramente casualizado (DIC), com seis tratamentos e cinco repetições de 20 sementes, sendo os resultados dos testes de germinação submetidos à análise de variância e as médias comparadas pelo teste Scott-Knott $(\mathrm{p}<0,05)$ com auxílio do programa estatístico SISVAR ${ }^{\circledR}$ (FERREIRA, 2014) e os gráficos confeccionados com auxílio do software SigmaPlot (SIGMAPLOT, 2008).

\section{RESULTADOS E DISCUSSÃO}

\subsection{AVALIAÇÕES BIOMÉTRICAS}

As medidas de tendência central, de variabilidade biométrica para assimetria e curtose, relacionadas ao comprimento, largura, espessura e massa de frutos e sementes de $H$. courbaril, revelam que os dados não seguem uma distribuição normal $(\mathrm{p} \leq 0,05)$ (Tabela 1$)$.

Desta maneira, ao analisar os dados biométricos dos frutos de $H$. courbaril pode-se constatar que os mesmos apresentaram comprimento médio com coeficiente de variação de $12 \%$ baseados na divisão dos valores do desvio padrão e média, com largura e espessura, apresentando variação de 11 e 16\%, respectivamente. Analisando ainda a massa total dos frutos observa-se que estes apresentaram variação considerável em relação à massa média, chegando a aproximadamente $28 \%$, cuja variabilidade, no que diz respeito aos dados de variação da divisão do desvio pela média dos dados, foi distribuída da seguinte maneira: casca, 25\%; semente, 50\%; e polpa 28\% (Tabela 1). 
Tabela 1. Estatística descritiva dos dados biométricos de frutos e sementes dos valores mínimo (MIN), máximo (MAX), médio (MED), desvio-padrão (DP), assimetria (ASS), curtose (CUR) e teste Shapiro-Wilk (SW) analisados para comprimento (C), largura (L), espessura (E), casca do fruto (CF), polpa (P) e semente (S) de Hymenaea courbaril L.

\begin{tabular}{|c|c|c|c|c|c|c|c|}
\hline \multirow{3}{*}{ Estatística } & \multicolumn{7}{|c|}{ FRUTOS } \\
\hline & \multicolumn{3}{|c|}{--- Biometria (mm) -.- } & \multicolumn{3}{|c|}{-.--- Massa (g) ---.-- } & \multirow[b]{2}{*}{ Total } \\
\hline & $\mathrm{C}$ & $\mathrm{L}$ & $\mathrm{E}$ & $\mathrm{CF}$ & $\mathrm{P}$ & $S$ & \\
\hline MIN & 79,40 & 34,60 & 24,00 & 24,35 & 4,62 & 2,76 & 31,73 \\
\hline MAX & 142,00 & 59,20 & 44,00 & 74,72 & 15,38 & 25,41 & 115,51 \\
\hline MED & 111,38 & 47,09 & 30,18 & 44,60 & 8,26 & 9,44 & 62,30 \\
\hline DP & 13,88 & 5,28 & 4,74 & 10,98 & 2,33 & 4,72 & 17,31 \\
\hline $\operatorname{ASS}^{(1)}$ & 0,198 & 0,031 & 1,012 & 0,452 & 1,036 & 1,217 & 0,827 \\
\hline $\mathrm{CUR}+3^{(2)}$ & 2,891 & 2,792 & 3,518 & 3,141 & 3,923 & 4,942 & 3,902 \\
\hline \multirow[t]{2}{*}{ SW (3) } & $0,589^{\mathrm{ns}}$ & $0,927^{\mathrm{ns}}$ & $0,001^{*}$ & $0,289^{\mathrm{ns}}$ & $0,003^{*}$ & $0,001^{*}$ & $0,026^{*}$ \\
\hline & \multicolumn{7}{|c|}{ SEMENTES } \\
\hline \multirow[t]{2}{*}{ Estatística } & \multicolumn{5}{|c|}{--- Biometria (mm) --- } & \multicolumn{2}{|c|}{---Massa (g) ---- } \\
\hline & \multicolumn{2}{|r|}{$\mathrm{C}$} & \multicolumn{2}{|c|}{$\mathrm{L}$} & $\mathrm{E}$ & \multicolumn{2}{|c|}{ Total } \\
\hline MIN & \multicolumn{2}{|r|}{17,20} & \multicolumn{2}{|c|}{11,40} & 8,50 & \multicolumn{2}{|r|}{1,80} \\
\hline MAX & \multicolumn{2}{|r|}{25,10} & \multicolumn{2}{|c|}{21,50} & 18,30 & \multicolumn{2}{|r|}{4,34} \\
\hline MED & \multicolumn{2}{|r|}{21,74} & \multicolumn{2}{|c|}{16,30} & 12,04 & \multicolumn{2}{|r|}{3,09} \\
\hline DP & \multicolumn{2}{|r|}{14,01} & \multicolumn{2}{|c|}{13,65} & 13,54 & \multicolumn{2}{|c|}{0,48} \\
\hline ASS $^{(1)}$ & \multicolumn{2}{|r|}{$-0,119$} & \multicolumn{2}{|c|}{$-0,322$} & 0,327 & \multicolumn{2}{|c|}{$-0,167$} \\
\hline $\mathrm{CUR}+3^{(2)}$ & \multicolumn{2}{|r|}{3,032} & \multicolumn{2}{|c|}{5,257} & 5,262 & \multicolumn{2}{|r|}{2,970} \\
\hline$S W^{(3)}$ & \multicolumn{2}{|r|}{$0,065^{\text {ns }}$} & \multicolumn{2}{|c|}{$0,001^{*}$} & $0,001 *$ & \multicolumn{2}{|c|}{$0,549^{\mathrm{ns}}$} \\
\hline
\end{tabular}

(1) Assimetria difere de zero, pelo teste t, ao nível de 5\% de probabilidade.

(2) Curtose difere de três, pelo teste $t$, ao nível de $5 \%$ de probabilidade.

(3) * Significativo a $5 \%$ de probabilidade, ${ }^{\text {ns }}$ não significativo.

Essa variação entre os coeficientes também foi verificada por Pereira et al. (2011) em frutos de Hymenaea stigonocarpa, os quais constataram que houve 23,4\% para comprimento, 17,8\% para largura e 13,6\% para espessura dos frutos. Variação esta superior aos encontrados neste trabalho para comprimento e largura e inferior para espessura. Segundo Abreu et al. (2017) esta variação dos valores atua como indicativo de heterogeneidade nas dimensões das sementes.

Considerando a divisão entre a massa média de cada constituinte dos 
frutos (casca, semente e polpa) e a massa total dos frutos, foi possível constatar que somente cerca de $15 \%$ de toda biomassa do fruto foi destinada ou alocada para as sementes, ficando o restante da biomassa alocada na casca, com cerca de $72 \%$, e a polpa farinácea com cerca de 13\% (Tabela 1).

Desta forma, na análise biométrica das estruturas que compõem o fruto, observa-se que a alocação de biomassa total do fruto foi translocada para massa da casca, valor este superior às demais estruturas. Isso pode ser explicado por Wright e Westoby (1999) que afirmam que a mudança na alocação se dá para órgãos que requerem mais fortemente os recursos limitantes, onde as respostas das plantas à variação no suprimento de nutrientes devem se deslocar para regiões que proporcionem um melhor desenvolvimento para formação de frutos.

Constatou-se ainda que os frutos analisados nesta pesquisa foram inferiores quanto ao comprimento e largura, quando comparados com aqueles estudados por Andrade et al. (2010) para a mesma espécie, que apresentaram valores médios de $115,70 \mathrm{~mm}$ de comprimento e $62,18 \mathrm{~mm}$ de largura. No mesmo gênero, Pereira et al. (2011), em frutos de Hymenaea stigonocarpa, verificaram em média 136,23 $\mathrm{mm}$ para comprimento, $48,32 \mathrm{~mm}$ para largura e $34,68 \mathrm{~mm}$ de espessura. Duarte et al. (2016) relataram para a mesma espécie $22,6 \mathrm{~mm}$ de comprimento, 17,7 $\mathrm{mm}$ de largura, 12,1 de espessura e 3,4 g de massa média.

Evidencia-se, então, que as variações no tamanho de frutos e sementes são influenciadas por fatores bióticos e abióticos decorrentes de elementos genéticos e/ou regionais (GOMES et al., 2016). Assim como confirmado por Moraes e Alves (2002), que ao estudarem os aspectos biométricos de frutos e sementes, verificaram que existe correlação parcial entre o ambiente e os fatores genéticos aos quais as espécies estão expostas, tendo em vista que existem variações genéticas e fenotípicas para uma mesma espécie quando analisadas em diferentes ambientes.

É importante salientar que é de fundamental importância à padronização dos frutos durante o processo de seleção e, posterior, homogeneização de amostras, visando à necessidade de obtenção de sementes qualificadas para reprodução da espécie ou diferenciação entre gêneros. Assim como constatado em H. courbaril, cujos frutos apresentam características cerca de quatro vezes maiores que os frutos de Hymenaea intermedia (CRUZ et al., 2001).

O conhecimento dos aspectos biométricos se reveste de maior importância 
quando esta análise é feita levando-se em consideração a alocação de biomassa nas sementes. Na avaliação das sementes extraídas dos frutos, os valores referentes ao desvio em divisão pela média de sementes apresentaram variação de cerca de $6 \%$ para comprimento; em relação à largura foram constatadas variação de $9 \%$ e para espessura obteve-se variação de cerca de $12 \%$, onde verificou-se ainda variação de $16 \%$ para massa média total das sementes de $H$. courbaril. Analisando a significância dos dados em relação ao teste Shapiro-Wilk, pode-se observar que apenas a espessura dos frutos e massa da polpa dos frutos, massa de sementes nos frutos, massa total dos constituintes dos frutos, assim como largura e espessura das sementes foram os constituintes que apresentaram efeito significativo em relação à biometria (Tabela $1)$.

Quanto à assimetria, os frutos apresentam distribuição assimétrica positiva, enquanto que as sementes são assimétricas negativas, com exceção da espessura. Esta relação implica que os frutos estão distribuídos com valores próximos ao máximo, enquanto que as sementes estão próximas ao mínimo. Quanto à curtose dos frutos e sementes com valores próximo ou superior a três, indicam que a distribuição de frequência é centralizada e, portanto, platicúrtica. De maneira geral, as medidas apresentaram ampla distribuição amostral quanto ao tamanho de frutos e sementes (Tabela 1).

Ao estudarem os aspectos biométricos de frutos e sementes de Melanoxylon brauna, Silva et al. (2013) relataram que os frutos apresentaram distribuição assimétrica e platicúrtica, enquanto que as sementes apresentaram largura com assimetria à esquerda e comprimento e espessura com assimetria à direita. Estimase que as variações decorrentes das características de frutos e sementes sejam influenciadas pela disponibilidade hídrica durante o desenvolvimento da planta (MARCOS FILHO, 2015).

Em análise das classes biométricas dos frutos de $H$. courbaril, pode-se verificar que 66\% apresentaram comprimento médio ou superior dos frutos (Figura 1A), de acordo com as classes de distribuição de frequência. Já para largura verificouse que $68 \%$ dos frutos apresentaram largura satisfatória (Figura 1B), com espessura com $74 \%$ dos frutos com valores médios ou superiores dentro das classes (Figura 1C) e observou-se que para as classes de massa total dos frutos houve percentual de $68 \%$, com valores médios ou superiores à média (Figura 1D). 

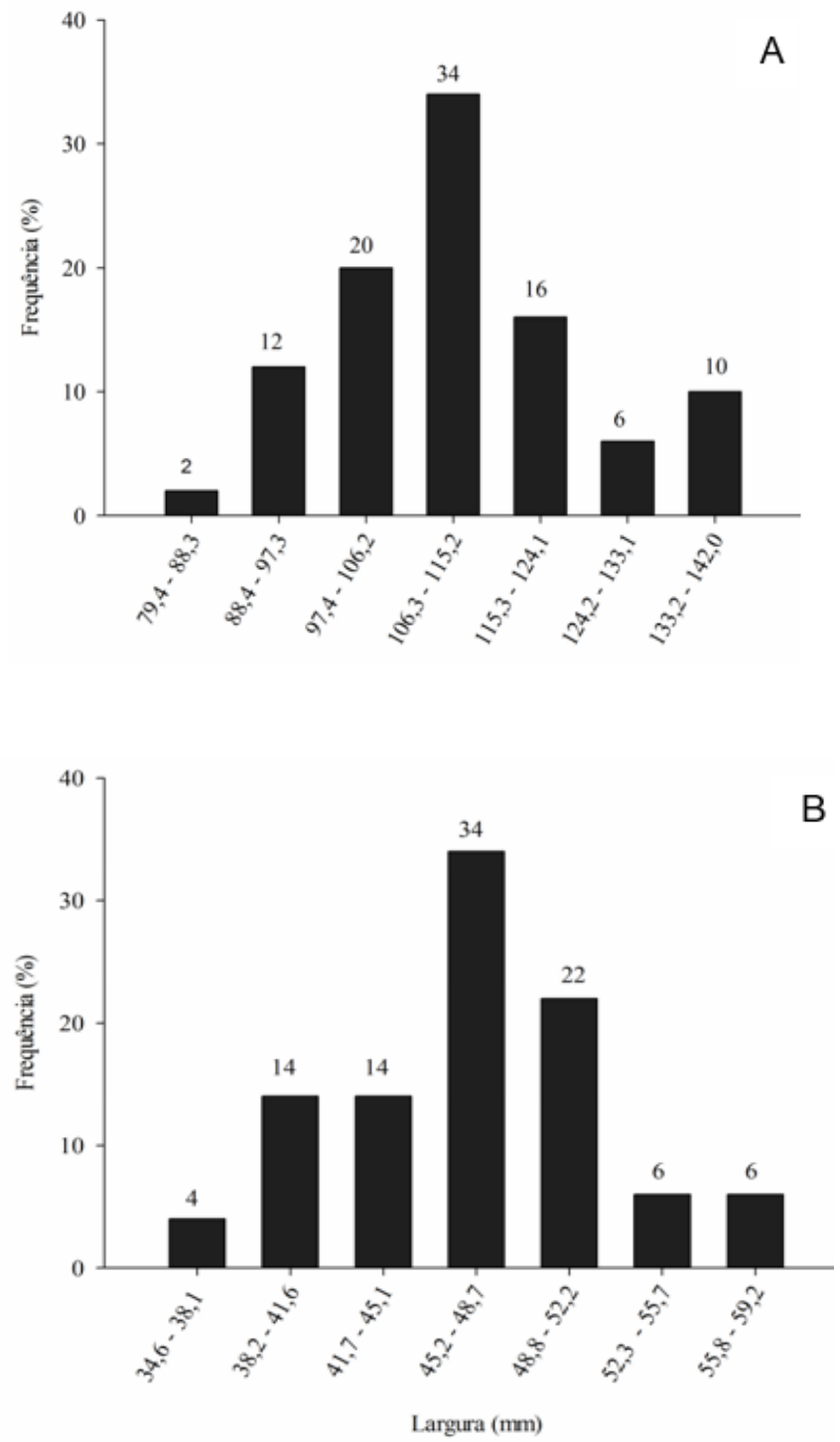
Comprimento (mm)

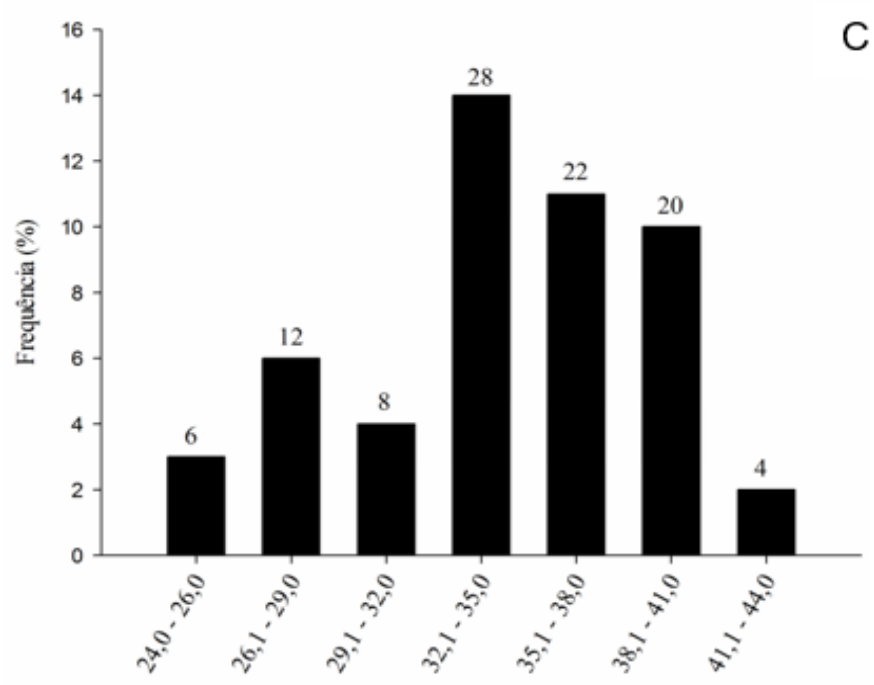

Espessura (mm)

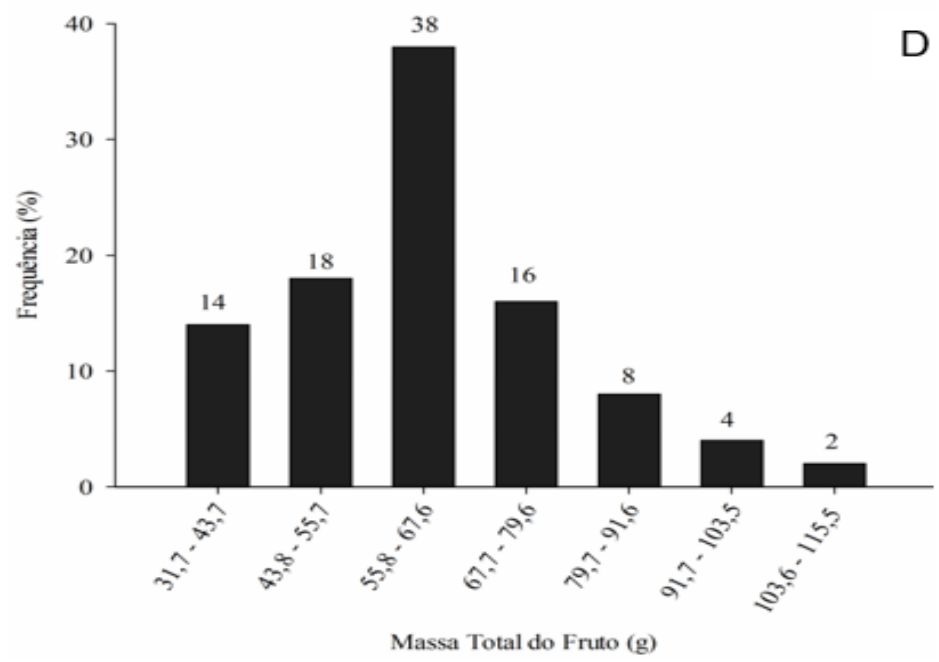

Figura 1. Classes de frequência para comprimento (A), largura (B), espessura (C) e massa total (D) de frutos de Hymenaea courbaril L. 
Ao analisar as classes biométricas das sementes, verificou-se que para comprimento médio de $H$. courbaril existe variação entre as classes com percentual de $78 \%$ das sementes com comprimento igual ou superior à média (Figura 2A). Quanto à largura, cerca de 69\% das sementes na largura satisfatória (Figura 2B), com espessura de $67 \%$ de sementes (Figura 2C). Constatou-se ainda que, do total de sementes obtidas dos frutos beneficiados, cerca de $68 \%$ apresentam massa igual ou superior à média da massa que está classificada a maioria das sementes (Figura 2D). Esta pode ser uma característica das espécies de ambientes secos, que sofrem déficit hídrico na época de frutificação, ocasionando sementes com massa e viabilidade variável.
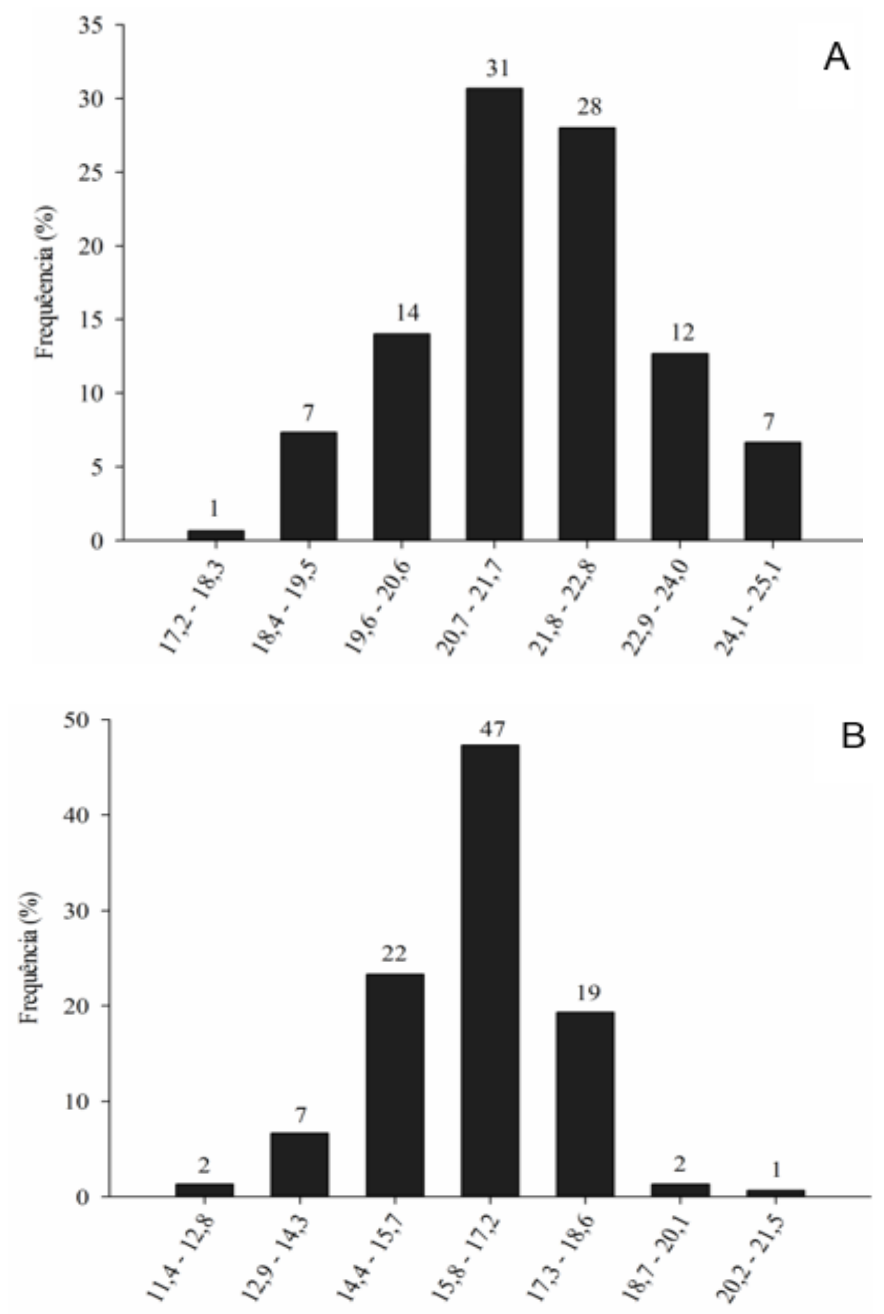


\section{Comprimento $(\mathrm{mm})$}

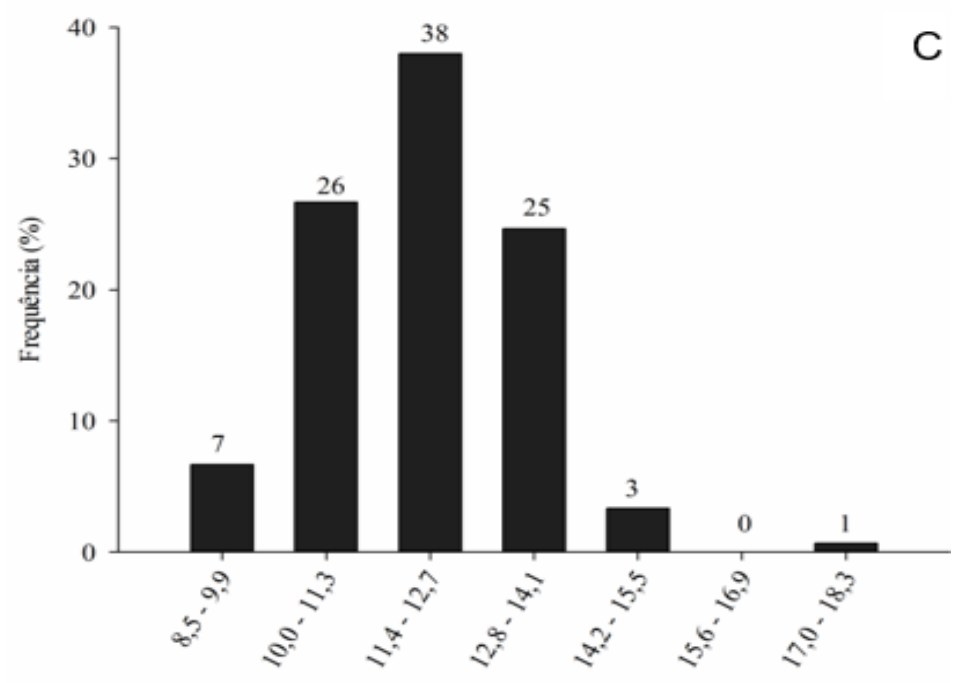

Espessura (mm)

\section{Largura (mm)}

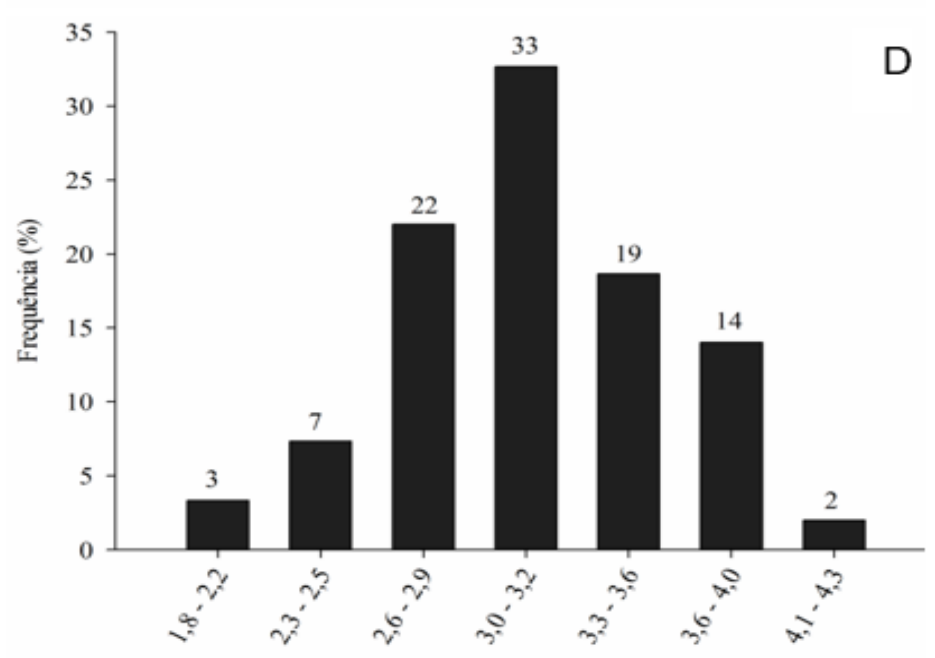

Massa Total de Sementes (g)

Figura 2. Classes de frequência para comprimento (A), largura (B), espessura (C) e massa total (D) de sementes de Hymenaea courbaril L. 
O tamanho das sementes, em muitas espécies, é indicativo de sua qualidade fisiológica, pois dentro do mesmo lote as sementes pequenas apresentam menores valores de germinação e vigor que as de tamanhos médio e grande, estando associada ao ambiente ao qual a planta mãe está inserida (SILVA et al., 2017; SANTOS et al., 2019). A remoção das sementes menores, durante o beneficiamento, pode melhorar a qualidade fisiológica do lote, e sementes já classificadas quanto ao tamanho podem ser separadas por outras características (POPINIGIS, 1977).

De maneira geral, pode ser considerado que as diferenças na partição de biomassa entre as estruturas dos frutos podem ocorrer devido às necessidades estruturais dos órgãos, por efeito da força do dreno, ou ainda como resposta das plantas à variação no suprimento de nutrientes/fotoassimilados, de maneira a proporcionar melhor desenvolvimento dos frutos.

\subsection{TESTE DE GERMINAÇÃO}

Ao analisar os métodos relativos à germinação, observou-se que para os tratamentos submetidos à escarificação com ácido sulfúrico durante 30 minutos, os quais resultaram em $80 \%$ de germinação, não diferiram estatisticamente da escarificação com lixa o qual resultou em 93\% da germinação (Tabela 2). Resultados semelhantes à escarificação mecânica foram obtidos nos trabalhos realizados por Cruz et al. (2011), Duarte et al. (2016). 
Tabela 2. Percentagem de germinação (GER), índice de velocidade de germinação (IVG) e tempo médio de germinação (TMG) - em dias - de sementes de jatobá (Hymenaea courbaril L.) submetidas a diferentes tratamentos para superação de dormência

\begin{tabular}{l|c|c|c}
\hline *Tratamentos & GER & IVG & TMG \\
\hline Controle & $15,56 \pm 9,93 \mathrm{c}$ & $0,05 \pm 0,04 \mathrm{c}$ & $9,75 \pm 6,13 \mathrm{a}$ \\
\hline $\mathrm{H}_{2} \mathrm{SO}_{4}-10$ & $44,44 \pm 17,57 \mathrm{~b}$ & $0,25 \pm 0,10 \mathrm{~b}$ & $18,85 \pm 9,46 \mathrm{~b}$ \\
\hline $\mathrm{H}_{2} \mathrm{SO}_{4}-20$ & $48,89 \pm 21,66 \mathrm{~b}$ & $0,35 \pm 0,19 \mathrm{~b}$ & $17,25 \pm 7,51 \mathrm{~b}$ \\
\hline $\mathrm{H}_{2} \mathrm{SO}_{4}-30$ & $80,00 \pm 4,97 \mathrm{a}$ & $0,65 \pm 0,07 \mathrm{a}$ & $22,05 \pm 4,12 \mathrm{~b}$ \\
\hline $\mathrm{Lixa}^{\circ} \mathrm{n}^{\circ} 80$ & $93,33 \pm 6,08 \mathrm{a}$ & $0,66 \pm 0,07 \mathrm{a}$ & $28,60 \pm 4,98 \mathrm{~b}$ \\
\hline $\mathrm{H}_{2} \mathrm{O}-100^{\circ} \mathrm{C}$ & $13,33 \pm 14,49 \mathrm{c}$ & $0,05 \pm 0,05 \mathrm{c}$ & $8,00 \pm 8,52 \mathrm{a}$ \\
\hline $\mathrm{CV}(\%)$ & 28,08 & 29,58 & 40,45 \\
\hline
\end{tabular}

Nas colunas, médias seguidas pela mesma letra minúscula não diferem entre si pelo teste Scott-Knott $(\mathrm{p}<0,05)$. *Tratamentos: Controle_sementes sem tratamento; $\mathrm{H}_{2} \mathrm{SO}_{4}$ - 10' _imersão das sementes em ácido sulfúrico durante 10 minutos; $\mathrm{H}_{2} \mathrm{SO}_{4}$ - 20' _ imersão das sementes em ácido sulfúrico durante 20 minutos; $\mathrm{H}_{2} \mathrm{SO}_{4}$ - 30' _ imersão das sementes em ácido sulfúrico durante 30 minutos; Lixa n ${ }^{\circ} 80$ _ escarificação mecânica com lixa n ${ }^{\circ} 80 ; \mathrm{H}_{2} \mathrm{O} 100^{\circ} \mathrm{C}$ _ imersão das sementes em água à temperatura de $100{ }^{\circ} \mathrm{C}$ até resfriamento.

A ação de métodos pré-germinativos em sementes com tegumento impermeável ocorre a partir do enfraquecimento do tegumento, que permite a entrada da água e oxigênio, além de favorecer a atuação de enzimas hidrolíticas que atuam com a ativação da síntese proteica, permitindo a mobilização de reservas provenientes do processo germinativo (DANTAS et al., 2008).

A escarificação das sementes através de métodos químicos utilizando ácido sulfúrico apresenta alta eficiência na superação e maior praticidade na escarificação de sementes para produção de mudas em larga escala, porém, do ponto de vista econômico é um método que exige um recurso maior para aquisição, além de necessitar de cuidados especiais durante a utilização e descarte. Já a escarificação mecânica utilizando lixa é um método eficiente e de baixo custo, porém torna-se trabalhoso, pois necessita da escarificação individual das sementes para produção em larga escala de mudas.

Resultados satisfatórios foram encontrados por Freitas et al. (2013) ao utilizarem ácido sulfúrico em sementes de Hymenaea courbaril durante 30 minutos, os quais obtiveram 56\% de emergência. A eficiência dos métodos pré-germinativos também foi constatada em sementes de Caesalpinia pyramidalis (ALVES et al., 2007), 
Leucaena diversifolia (SOUZA et al., 2007), Myracrodruon urundeuva (GUEDES et al., 2009), Hymenaea courbaril (ANDRADE et al., 2010; FREITAS et al., 2013; DUARTE et al., 2016; SANTOS et al., 2019), Colubrina glandulosa (BRANCALION et al., 2011), Sesbania virgata (SILVA et al., 2011), Baubinia forficata (COSTA et al., 2013) e Tachigali vulgaris (ABREU et al., 2017).

Estes resultados revelam que as sementes utilizadas neste experimento apresentam características ecofisiológicas mais acentuadas por se tratarem de uma espécie adaptada à região de clima seco e por isso manifestam elevada intensidade de dormência, necessitando de métodos com maior poder corrosivo para rompimento do tegumento duro.

Tais características estão relacionadas às alterações genéticas das espécies resultantes do processo adaptativo e variam de acordo com o ambiente ao qual estão expostas. Para maior proteção do embrião os tecidos tegumentares responsáveis pela impermeabilidade e dureza aumentam a espessura e atuam com bloqueio das trocas gasosas, restringindo a oxigenação e embebição do embrião (BORGES et al., 2004).

$\mathrm{Na}$ análise do índice de velocidade de germinação (IVG), o tratamento que consistiu na utilização do ácido sulfúrico por 30 minutos e lixa foram aqueles que apresentaram melhores resultados, com IVG de 0,65 e 0,66, respectivamente (Tabela 2). Em estudos realizados por Costa et al. (2013), com tratamentos para superar a dormência de Baubinia forficata, relataram que os maiores valores de IVG foram encontrados ao submeterem as sementes aos tratamentos com ácido sulfúrico e lixa, os quais diferiram dos demais tratamentos. Da mesma forma, o alto vigor em sementes utilizando ácido sulfúrico em Myracrodruon urundeuva também foram relatados por Guedes et al. (2009); já Souza et al. (2015) relataram para Hymenaea martiana Hayne IVG de 0,94 com germinação de 66\% e para a espécie Hymenaea courbaril IVG de 0,98 e 74,3\% de germinação.

O melhor tempo médio de germinação (TMG) foi obtido com os tratamentos em ácido sulfúrico 30 minutos e lixa, os quais apresentaram um período médio de germinação que se prolongaram até 22 e 29 dias, respectivamente (Tabela 2). Para a espécie de $H$. courbaril estes tratamentos foram considerados os melhores, pois germinaram durante todo o período de avaliação, ao contrário 
dos demais tratamentos que apresentaram baixa germinação e TMG com até nove dias. Da mesma maneira, Cruz et al. (2001) constataram melhor TMG (18,9 dias) ao realizarem a superação de dormência em sementes de Hymenaea intermédia através da escarificação mecânica.

$\mathrm{Na}$ imersão das sementes em água quente $\left(100{ }^{\circ} \mathrm{C}\right.$ até atingir o resfriamento) a germinação foi de $13,33 \%$, valor este considerado extremamente baixo, percentualmente inferior quando comparado ao tratamento controle com germinação de $15,55 \%$. Desta forma, este método de superação através da água quente nas sementes de $H$. courbaril revelou-se ineficiente, permitindo as sementes permanecerem intactas ou causando a morte de aproximadamente $87 \%$ das sementes, as quais não apresentaram indício de absorção de água.

Resultados insatisfatórios para a superação de dormência das sementes utilizando água quente foram relatados por Ataíde et al. (2013) na espécie de Delonix regia utilizando água a $90^{\circ} \mathrm{C}$ durante 1 minuto; por Costa et al. (2013), em sementes de Baubinia forficata que foram submetidas a $80^{\circ} \mathrm{C}$ por 2 e 5 minutos; por Abreu et al. (2017) em sementes de Tachigali vulgaris na temperatura de $80{ }^{\circ} \mathrm{C}$ por 24 horas e por Montanha et al. (2018) em sementes de Desmodium tortuosum em imersão em água a $100{ }^{\circ} \mathrm{C}$ até o resfriamento.

Em contrapartida, Smiderle et al. (2005) encontraram resultados promissores ao submeterem sementes de Acacia mangium a tratamentos pré-germinativos à temperatura elevada, e recomendaram o tratamento de sementes por um minuto em água a $100{ }^{\circ} \mathrm{C}$, apresentando eficiência na superação de dormência tegumentar com $92 \%$ de germinação. Da mesma forma, Souza et al. (2007) ao estudarem a superação de dormência de Leucaena diversifolia encontraram resultados promissores utilizando água a $100{ }^{\circ} \mathrm{C}$ por um minuto na superação dessa espécie com $61 \%$ de germinação.

As contradições de resultados em espécies florestais utilizando água quente estão relacionadas aos fatores ambientais, genéticos, maturação ou tempo de exposição das sementes à temperatura elevada. Em relação à testemunha, foi possível constatar que as sementes de $H$. courbaril apresentam baixa percentagem de germinação, inferindo que esta espécie necessita da utilização de tratamentos pré-germinativos para superação de dormência. 


\section{CONSIDERAÇÕES FINAIS}

Os frutos e sementes de $H$. courbaril apresentam ampla variação quanto aos aspectos biométricos e de biomassa.

A alocação de biomassa dos constituintes dos frutos em relação à massa total foi distribuída com cerca de $15 \%$ para as sementes, $72 \%$ para a casca dos frutos e cerca de $13 \%$ alocada para a polpa farinácea, das quais cerca de $68 \%$ das sementes foram classificadas com massa igual ou superior à média das classes de 2,90 a 4,34 g.

Os tratamentos mais indicados para superação de dormência das sementes foram obtidos através do método químico, com a submissão das sementes em ácido sulfúrico concentrado por 30 minutos e o método físico, através da escarificação mecânica com lixa para as sementes de H. courbaril.

\section{AGRADECIMENTOS}

À Fundação de Amparo à Pesquisa do Estado de Alagoas (FAPEAL), ao Centro de Referência em Recuperação de Áreas Degradadas do Baixo São Francisco (CRAD), e à UFAL-Arapiraca, pelo apoio logístico, técnico e financeiro.

\section{REFERÊNCIAS}

ABREU, D. C. A.; PORTO, K. G.; NOGUEIRA, A. C. Métodos de superação da dormência e substratos para germinação de sementes de Tachigali vulgaris L.G. Silva \& H. C. Lima. Floresta Ambient., v. 24, e00071814, 2017.

ALVES, E. U.; CARDOSO, E. A.; BRUNO, R. L. A.; ALVES, A. U.; ALVES, A. U.; GALINDO, E. A.; BRAGA-JÚNIOR, J. M. Superação de dormência em sementes de Caesalpinia pyramidalis Tul. Revista Árvore, v. 31, n. 3, p. 405-415, 2007.

ANDRADE, L. A.; BRUNO, R. L. A.; OLIVEIRA, L. S. B.; SILVA, H. T. F. Aspectos biométricos de frutos e sementes, grau de umidade e superação de dormência de jatobá. Acta Scientiarum. Agronomy, v. 32, n. 2, p. 293-299, 2010. 
ATAÍDE, G. M.; BICALHO, E. M.; DIAS, D. C. F. S.; CASTRO, R. V. O.; Alvarenga, E. M. Superação da dormência das sementes de Delonix regia (Bojer ex Hook.) Raf. Revista Árvore, v. 37, n. 6, p. 1145-1152, 2013.

BEWLEY, J. D.; BLACK, M. Seeds: physiology of development and germination. New York: Plenum Press, 1994.

BORGES, E. E. L. et al. Alterações fisiológicas em sementes de Tachigalia multijuga (Benth.) (Mamoneira) relacionadas aos métodos para a superação da dormência. Revista Árvore, v. 28, n. 3, p. 317-325, 2004.

BRANCALION, P. H. S.; MONDO, V. H. V.; NOVEMBRE, A. D. L. C. Escarificação química para a superação da dormência de sementes de saguaraji-vermelho (Colubrina glandulosa Perk. - Rhamnaceae). Revista Árvore, v. 35, n. 1, p. 119-124, 2011.

BRASIL. Ministério da Agricultura, Pecuária e Abastecimento. Regras para análise de sementes. Ministério da Agricultura, Pecuária e Abastecimento. Secretaria de Defesa Agropecuária. Brasília: MAPA/ACS, 2009. 395p.

CARVALHO, N. M.; NAKAGAWA, J. (ed.). Sementes: ciência, tecnologia e produção. 5. ed. Jaboticabal: Funep, 2012. 590p.

CARVALHO, P. E. R. Espécies florestais brasileiras: recomendações silviculturais, potencialidades e uso da madeira. Brasília: EMBRAPA/CNPF, 1994. 640p.

COSTA, E. S.; SANTOS NETO, A. L.; COSTA, R. N.; SILVA, J. V.; SOUZA, A. A.; SANTOS, V. R. Dormência de sementes e efeito da temperatura na germinação de sementes de mororó. Revista de Ciências Agrárias, v. 56, n. 1, p. 19-24, 2013.

CRUZ, E. D.; MARTINS, F. O; CARVALHO, J. E. U. Biometria de frutos e sementes e germinação de jatobá-curuba (Hymenaea intermedia Ducke, Leguminosae - Caesalpinioideae). Revista Brasileira de Botânica, v. 24, n. 2, p. 161-165, 2001.

DANTAS, B. F.; CORREIA, J. S.; MARINHO, L. B.; ARAGAO, C. A. Alterações bioquímicas durante a embebição de sementes de catingueira (Caesalpinia pyramidalis Tul.). Revista Brasileira de Sementes, v. 30, n. 1, p. 221-227, 2008. 
DUARTE, M. M.; PAULA, S. R. P.; FERREIRA, F. R. L.; NOGUEIRA, A. C. Morphological characterization of fruit, seed and seedling and germination of Hymenaea courbaril L. (Fabaceae) ('Jatobá'). Journal of Seed Science, v. 38, n. 3, p. 204-211, 2016.

DUARTE, M. M.; MILANI, J. E. F.; BLUM, C. T.; NOGUEIRA, A. C. Germinação e morfologia de sementes e plântulas de Albizia edwallii (Hoehne) Barneby \& J. W. Grimes. Revista Caatinga, v. 28, n. 3, p. 166-173, 2015.

FERREIRA, D. F. Sisvar: a Guide for its Bootstrap procedures in multiple comparisons. Ciência e Agrotecnologia, v. 38, p. 109-112, 2014.

FREITAS, A. R.; LOPES, J. C.; MATHEUS, M. T.; MENGARDA, L. G.; VENANCIO, L. P.; CALDEIRA, M. V. W. Superação da dormência de sementes de jatobá. Pesquisa Florestal Brasileira, v. 33, n. 73, p. 85-90, 2013.

GOMES, D. R.; ARAUJO, M. M.; NUNES, U. R.; AIMI, S. C. Biometry and germination of Balfourodendron riedelianum Eng. Journal of Seed Science, v. 38, p. 187-194, 2016.

GONÇALVES, L. G. V.; ANDRADE, F. R.; MARIMON JUNIOR, B. H.; SCHOSSLER, T. R.; LENZA, E.; MARIMON, B. S. Biometria de frutos e sementes de mangaba (Hancornia speciosa Gomes) em vegetação natural na região leste de Mato Grosso, Brasil. Revista de Ciências Agrárias, v. 36, n. 1, p. 31-40, 2013.

GUEDES, R. S.; ALVES, E. U.; GONÇALVES, E. P.; COLARES, P. N. Q.; MEDEIROS, M. S.; SILVA, K. B. Tratamentos pré-germinativos em sementes de Myracrodruon urundeuva Freire Allemão. Revista Árvore, v. 33, n. 6, p. 997-1003, 2009.

GUSMÃO, E.; VIEIRA, F. A.; FONSECA JÚNIOR, E. M. Biometria de frutos e endocarpos de murici (Byrsonima verbascifolia Rich. ex A. Juss.) Revista Cerne, v. 12, n. 1, p. 84-91, 2006.

MARCOS FILHO, J. Fisiologia de sementes de plantas cultivadas. 2. ed. Londrina: ABRATES, 2015. 659 p. 
MATHEUS, M. T.; AMARAL, J. A. T.; SILVA, D. G. G.; NEVES, D. M.; PIZZOL, E. C. S.; SOUSA, F. C.; SANTI, G. C.; GUARIZ, H. R.; LIMA, K. A.; HOFFMANN, R. G. Sintomas de deficiência nutricional em Jatobá. Revista Científica Eletrônica de Engenharia Florestal, v. 17, n. 1, p. 89-97, 2011.

MATOS, A. C. B.; ATAIDE, G. M.; BORGES, E. E. L. Physiological, physical, and morpho-anatomical changes in Libidibia ferrea ((Mart. ex Tul.) L.P. Queiroz) seeds after overcoming dormancy. Journal of Seed Science, v. 37, n. 1, p. 26-32, 2015.

MONTANHA, D. A.; ALVES, J. M. A.; SILVA, M. R.; MATOS, W. S.; SILVA, D. C. O.; BARRETO, G. F. Superação dadormência e influência da profundidade de semeadura na germinação de sementes de Desmodium tortuosum. Revista Agro@mbiente On-line, v. 12, n. 1, p. 34-40, 2018.

MORAES, P. L. R.; ALVES, M. C. Biometria de frutos e diásporos de Cryptocarya aschersoniana Mez e Cryptocarya moschata Nees (Lauraceae). Biota Neotropica, v. 2, n. 1, p. 1-11, 2002.

PEREIRA, S. R.; GIRALDELLI, G. R.; LAURA, V. A.; SOUZA, A. L. T. Tamanho de frutos e de sementes e sua influência na germinação de jatobá-do-cerrado (Hymenaea stigonocarpa var. stigonocarpa Mart. ex Hayne, Leguminosae - Caesalpinoideae). Revista Brasileira de Sementes, v. 33, n. 1, p. 141-148, 2011.

PIRES NETO, P. A. F.; PIRES, V. C. M.; MORAES, C. B.; OLIVEIRA, L. M.; PORTELLA, A. C. F.; NAKAGAWA, J. Physiological ripening of Anadenanthera colubrina (Vellozo) Brenan seeds. Journal of Seed Science, v. 38, p. 155-161, 2016.

POPINIGIS, F. Qualidade fisiológica da semente. In: POPINIGIS, F. Fisiologia da semente. 2. ed. Brasília: Abrates, 1977, p. 157-247.

SANTOS, J.C.C.; LIMA, A.N.S.; SILVA, D.M.R.; COSTA, R.N.; AMORIM, D.J.; SILVA, J.V.; SANTOS NETO, A.L. Análise biométrica multidimensional com tratamentos pré-germinativos em sementes e caracterização morfológica de plântulas de Mimosa bimucronata (De Candolle) Otto Kuntze. Revista de Ciências Agrárias, v. 42, p.418-429, 2019. 
SANTOS, J.C.C.; SILVA, D.M.R.; COSTA, R.N.;SILVA, C.H.; SANTOS, W.S.; MOURA, F. B. P.; SILVA, J.V. Aspectos biométricos e morfológicos de frutos e sementes de Schinopsis brasiliensis. Nativa, v. 6, p. 219-224, 2018.

SANTOS, P. L.; FERREIRA, R. A.; ARAGÃO, A. G.; AMARAL, L. A.; OLIVEIRA, A. S. Estabelecimento de espécies florestais nativas por meio de semeadura direta para recuperação de áreas degradadas. Revista Árvore, v. 36, p. 237-245, 2012.

SIGMA PLOT. For windows, version 10.0 Systat Software, 2008.

SILVA, A. L.; DIAS, D. C. F. S.; LIMA, L. B.; MORAIS, G. A. Methods for overcoming seed dormancy in Ormosia arborea seeds, characterization and harvest time. Journal of Seed Science, v. 36, p. 318-325, 2014.

SILVA, B. M. S.; CARVALHO, N. M. Efeitos do estresse hídrico sobre o desempenho germinativo da semente de faveira (Clitoria fairchildiana R.A. Howard. - Fabaceae) de diferentes tamanhos. Revista Brasileira de Sementes, v. 30, n. 1, p. 55-65, 2008.

SILVA, M. S.; BORGES, E. E. L.; LEITE, H. G.; CORTE, V. B. Biometria de frutos e sementes de Melanoxylon brauna Schott. (Fabaceae-Caesalpinioideae). Cerne, v. 19, n. 3, p. 517-524, 2013.

SILVA, P. E. M.; SANTIAGO, E. F.; DALOSO, D. M.; SILVA, E. M.; SILVA, J. O. Quebra de dormência em sementes de Sesbania virgata (Cav.) Pers. Idesia, v. 29, n. 2, p. 39-45, 2011.

SILVA, R. M.; CARDOSO, A. D.; DUTRA, F. V.; MORAIS, O. M. Aspectos biométricos de frutos e sementes de Caesalpinia ferrea Mart. ex Tul. provenientes do semiárido baiano. Revista de Agricultura Neotropical, v. 4, n. 3, p. 85-91, 2017.

SMIDERLE, O. J.; OLIVEIRA JÚNIOR, M. C. M.; SOUSA, R. C. P. Tratamentos pré-germinativos em sementes de acácia. Revista Brasileira de Sementes, v. 27, n. 1, p. 78-85, 2005.

SOUZA, E. R. B.; ZAGO, R.; GARCIA, J.; FARIAS, J. G.; CARVALHO, E. M. S.; BAR- 
ROSO, M. R. Efeito de métodos de escarificação do tegumento em sementes de Leucaena diversifolia L. Pesquisa Agropecuária Tropical, v. 37, n. 3, p. 142-146, 2007.

SOUZA, P. F.; SANTANA, R. C.; FERNANDES, J. S. C.; OLIVEIRA, L. F. R.; MACHADO, E. L. M.; NERY, M. C.; OLIVEIRA, M. L. R. Germinação e Crescimento Inicial Entre Matrizes de Duas Espécies do Gênero Hymenaea. Floresta e Ambiente, v. 22, n. 4, p. 532-540, 2015.

TAMAYO, L. M. A.; GONZALEZ, D. M. A.; GARCES, Y. J. Propriedades farmacológicas del Algarrobo (Hymenaea courbaril Linneaus) de interés para la industria de alimentos. Revista Lasallista de Investigación, v. 5, n. 2, p. 100-111, 2008.

WRIGHT, I. J.; WESTOBY, M. Differences in seedling growth behavior among species: trait correlations across species, and traits shifts along nutrient compared to rainfall gradients. Journal of Ecology, v. 87, p. 85-97, 1999.

Recebido em: 15/03/2017

Aceito em: 24/07/2018 